\title{
Nature nurtures the design of new semi-synthetic macrolide antibiotics
}

\author{
Prabhavathi Fernandes, Evan Martens and David Pereira
}

Erythromycin and its analogs are used to treat respiratory tract and other infections. The broad use of these antibiotics during the last 5 decades has led to resistance that can range from $20 \%$ to over $70 \%$ in certain parts of the world. Efforts to find macrolides that were active against macrolide-resistant strains led to the development of erythromycin analogs with alkyl-aryl side chains that mimicked the sugar side chain of 16 -membered macrolides, such as tylosin. Further modifications were made to improve the potency of these molecules by removal of the cladinose sugar to obtain a smaller molecule, a modification that was learned from an older macrolide, pikromycin. A keto group was introduced after removal of the cladinose sugar to make the new ketolide subclass. Only one ketolide, telithromycin, received marketing authorization but because of severe adverse events, it is no longer widely used. Failure to identify the structure-relationship responsible for this clinical toxicity led to discontinuation of many ketolides that were in development. One that did complete clinical development, cethromycin, did not meet clinical efficacy criteria and therefore did not receive marketing approval. Work on developing new macrolides was re-initiated after showing that inhibition of nicotinic acetylcholine receptors by the imidazolyl-pyridine moiety on the side chain of telithromycin was likely responsible for the severe adverse events. Solithromycin is a fourth-generation macrolide that has a fluorine at the 2-position, and an alkyl-aryl side chain that is different from telithromycin. Solithromycin interacts at three sites on the bacterial ribosome, has activity against strains resistant to older macrolides (including telithromycin), and is mostly bactericidal.

Pharmaceutical scientists involved in the development of macrolide antibiotics have learned from the teachings of Professor Satoshi Omura and progress in this field was not possible without his endeavors.

The Journal of Antibiotics (2017) 70, 527-533; doi:10.1038/ja.2016.137; published online 30 November 2016

\section{INTRODUCTION}

The term 'macrolide' antibiotic to physicians and microbiologists means erythromycin and its analogs, such as clarithromycin, azithromycin and roxithromycin. Clarithromycin and roxithromycin possess a 14-membered macrocyclic ring, whereas azithromycin is 15 -membered. The 14-membered ring in erythromycin was expanded semi-synthetically by an introduction of a nitrogen to make the 15-membered macrolide, azithromycin. ${ }^{1}$ The large family of 16-membered macrolide antibiotics, with tylosin being the leader, is mostly used in veterinary practice. There are many hundreds of macrolide antibiotics that belong to these classes that have been described in detail by Professor Satoshi Omura in the book, Macrolide Antibiotics: Chemistry, Biology, and Practice. ${ }^{2}$ This book is essential reading for those interested in macrolide antibiotics, as it covers not only chemistry but also pharmacokinetics and structure-activity relationships that have been learned and re-learned over the decades. Additional macrocylic natural products, such as fidaxomicin, are sometimes referred to as macrolides but are not considered in this review as they are not related to erythromycin and also have a different mechanism of action. ${ }^{3}$

Erythromycin and its analogs have been widely used in medicine to treat respiratory, genital and skin infections. The properties of the macrolide class that support their use include: (i) good oral bioavailability, (ii) high concentrations in tissues and fluids such as the lung and pulmonary epithelial lining fluid, (iii) meaningful intracellular concentration, (iv) limited spectrum of activity that does not eradicate anaerobic Gram-negative microflora, especially in the intestine where these organisms play a protective role and (v) a profile of being generally safe and well-tolerated. The macrolides also have strong anti-inflammatory properties that provide symptomatic relief from the pain from inflammatory cytokines that are released at the sites of infection. ${ }^{4}$ All of these characteristics have led to macrolides being among the most successful of antibiotic classes in the outpatient setting as well as in the hospital.

\section{ERYTHROMYCIN AND SEMI-SYNTHETIC ANALOGS}

Erythromycin, a fermentation product from the bacteria Saccharopolyspora erythreus, was isolated in 1949 from a soil sample collected in the Philippines that was part of an intense screening program to find new antibiotics by Eli Lilly and Co. ${ }^{5}$ Although orally bioavailable, the macrocyclic ring is not stable in acid. At gastric $\mathrm{pH}$, there is conversion to anhydro-erythromycin, loss in antibacterial activity, and nausea and vomiting. ${ }^{6}$ The instability of the macrolide core ring to acidic environments is an advantage for the soil microbe that 


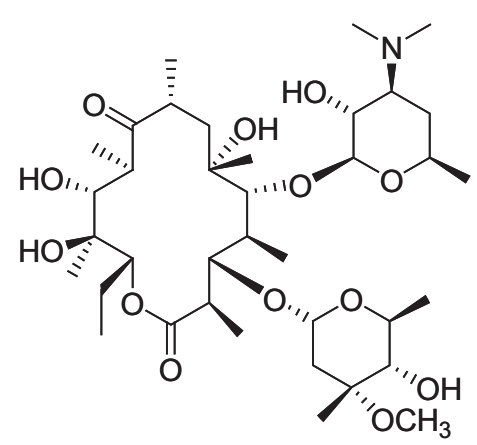

Erythromycin

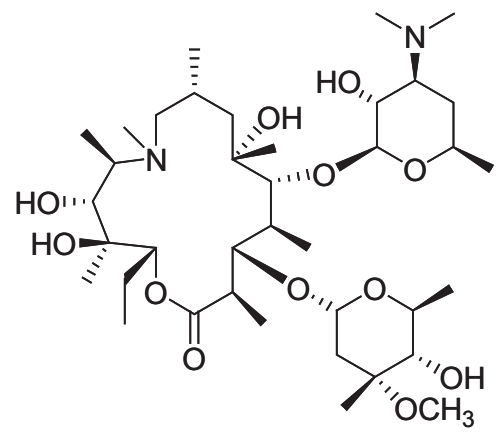

Azithromycin

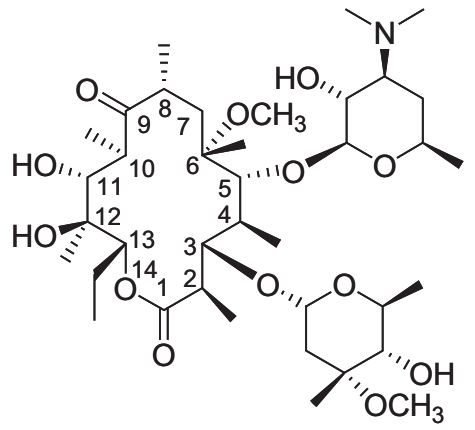

Clarithromycin

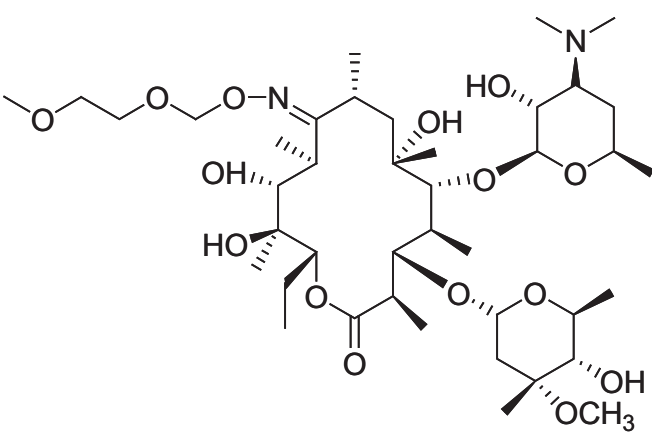

Roxithromycin

Figure 1 Chemical structures of erythromycin, clarithromycin, azithromycin and roxithromycin.

synthesizes it, because the antibiotic defends the immediate environment around the producing organism but does not persist in nature. Thus, from nature's point of view, it had made a perfect molecule. However, from the pharmaceutical point of view, improvements in acid stability was a necessity. Efforts to stabilize the ring led to the discovery of acid-stable, second-generation macrolide antibiotics such as roxithromycin, clarithromycin and azithromycin (Figure 1). The broad success of azithromycin has selected for bacterial resistance to azithromycin, erythromycin and clarithromycin, all of which share the same binding site on the bacterial ribosome. In 2015, resistance to these macrolides reached $48 \%$ in the US and over $70 \%$ in Asia. ${ }^{7,8}$

\section{MODIFICATIONS BASED ON THE 16-MEMBERED MACROLIDES}

The 16-membered macrolides like tylosin are less potent than erythromycin against macrolide-susceptible strains, possibly due to lower permeability across bacterial membranes, but are active against bacteria resistant to the 14-membered macrolides. ${ }^{9}$ Examination of the structure and activity of tylosin (Figure 2), before knowledge of the co-crystal structures of bacterial ribosomes and macrolides, suggested that the extra side chain of sugars in the 16-membered macrolides might be interacting with the ribosome at additional sites thereby overcoming resistance. ${ }^{10}$ In 1972, Omura et al., described structureactivity relationships of the 16-membered macrolides. ${ }^{11}$ This class of macrolides have complex sugar side chains and activity against macrolide-resistant strains. Many of the 16-membered macrolides such as tylosin, rokitamycin and midecamycin have been used to treat human and veterinary infections. However, the 16-membered macrolides had less in vivo efficacy than the 14- and 15-membered macrolides because metabolism of the side chains lead to metabolites with decreased or no activity. ${ }^{10}$ Therefore, more stable side chains carrying 11, 12 carbamates were synthesized at Abbott. ${ }^{10}$ Several compounds were shown to have activity against macrolide-resistant bacteria, but as was the case for tylosin, these had decreased overall potency. A macrolide antibiotic with improved activity remained elusive.

\section{MODIFICATIONS BASED ON PIKROMYCIN AND TYLOSIN}

Pikromycin, a 14-membered macrolide without a cladinose sugar (Figure 3), was the first macrolide antibiotic identified ${ }^{12}$ but due to low activity, it was not developed and erythromycin became the core for new macrolide development. Learning from tylosin and pikromycin chemistry, chemists at the pharmaceutical company, Aventis, designed telithromycin (Figure 4). In telithromycin, a side chain at the 11, 12-position simulated the sugar side chain of the 16-membered macrolides and a keto group replaced the cladinose, making the molecule smaller like pikromycin. ${ }^{6,9}$ As with the compounds made at Abbott Laboratories, telithromycin had activity against macrolideresistant strains, but also had 4-8-fold greater potency than the older macrolides. ${ }^{13}$ Co-crystal structures confirmed that like the older macrolides, telithromycin bound to the peptide tunnel on the $23 \mathrm{~S}$ RNA of the $50 \mathrm{~S}$ ribosome, and interacted with Domain V binding to A2058 and A2059. In addition, it also interacted distantly at Domain II via the side chain. ${ }^{14}$ Telithromycin's activity against macrolideresistant bacteria is reportedly due to the fact that telithromycin interacts with the bacterial ribosome at two distinct sites. ${ }^{15}$

\section{TELITHROMYCIN AND SEVERE ADVERSE EVENTS}

Telithromycin was approved for broad use by regulatory agencies to treat simple and complicated upper and lower respiratory tract infections. It is marketed under the brand name Ketek, derived from the macrolide subclass ketolide, which recognized the keto group in 


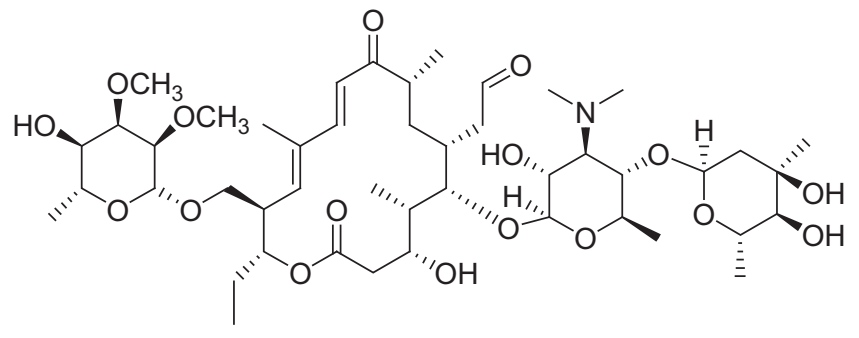

Tylosin

Figure 2 Chemical structure of tylosin, a 16-membered macrolide.

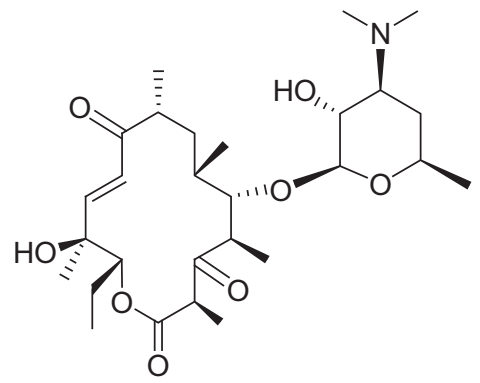

Figure 3 Chemical structure of pikromycin, a 14-membered macrolide and the first identified.

the molecule. Soon after approval, several severe adverse events became known, which were collectively called the 'Ketek effects'. These adverse events included reversible visual disturbance, syncope, exacerbation of myasthenia gravis and hepatic failure. ${ }^{16,17}$ The US Food and Drug Administration (FDA) withdrew its approval for simple infections and allowed its use for community-acquired bacterial pneumonia. ${ }^{18}$ However, due to the severe nature of the adverse events and the available alternatives, telithromycin is no longer widely used.

\section{OTHER KETOLIDES}

Several companies developed competitive programs to synthesize ketolide analogs like telithromycin in the late 1990's and the early 2000's. Cethromycin, a ketolide that had a side chain at the C6 position, unlike others, which were modifications at the $\mathrm{C} 11-\mathrm{C} 12$ position or on the cladinose ring, was synthesized and tested in early clinical trials at Abbott, but then licensed to the start-up company, Advanced Life Sciences. ${ }^{19}$ Advanced Life Sciences completed Phase 3 clinical trials, but failed to demonstrate efficacy in more severe respiratory infections and cethromycin was demonstrated to be noninferior to clarithromycin at the lowest approved dose of $250 \mathrm{mg}$ of clarithromycin in simple pneumonia. ${ }^{20}$ The dose used for cethromycin provided free blood levels that were low as over $95 \%$ of cethromycin is bound to plasma protein. ${ }^{20}$ Also, low blood levels were noted with repeated administration which was likely due to the compound's induction of CYP3A4, inducing its own metabolism and gastrointestinal tract effects, precluding doses sufficient to achieve clinical efficacy. ${ }^{20}$ The drug did not obtain marketing approval. Enanta Pharmaceuticals and Shionogi developed a modithromycin, but clinical development was halted. ${ }^{21}$ Hindered by the Ketek adverse event profile (thus far unexplained, but considered to possibly be related to the ketolide structure), Abbott, Merck, Johnson and Johnson, Pfizer, Kosan and other pharmaceutical companies terminated their ketolide programs. ${ }^{22}$

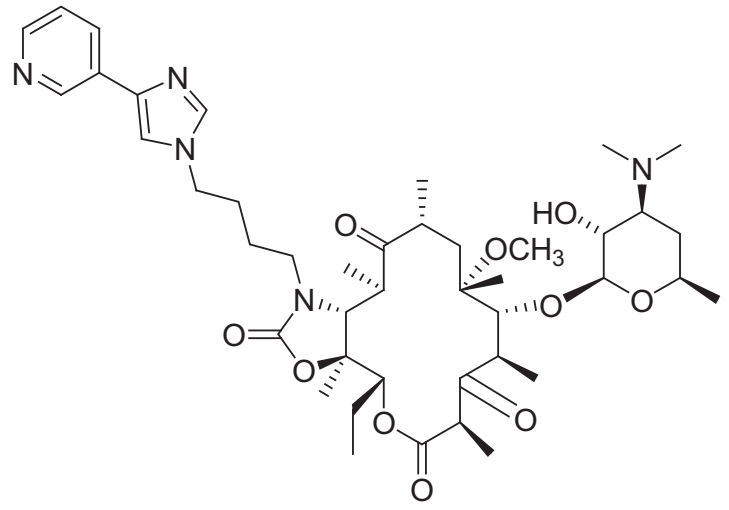

Figure 4 Chemical structure of telithromycin (Ketek), the first ketolide.

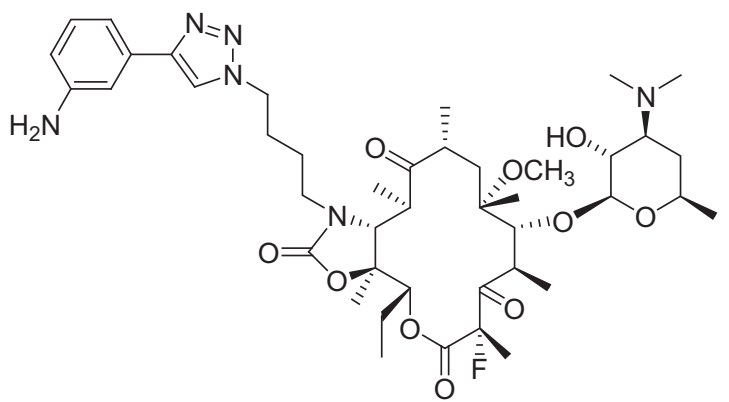

Figure 5 Chemical structure of solithromycin, a 4th-generation macrolide.

\section{SOLITHROMYCIN-THE FIRST FLUOROKETOLIDE}

In addition to the companies noted above, Optimer Pharmaceuticals, a small biopharmaceutical company in San Diego, had likewise generated a library of macrolides and ketolides using their expertise in macrolide and carbohydrate chemistries. From the library, licensed to Cempra Pharmaceuticals, Inc. in 2006, Cempra selected solithromycin for clinical development (Figure 5). ${ }^{23}$ Conclusive experiments performed by Dr Daniel Bertrand and his staff demonstrated that telithromycin blocked the activity of key nicotinic acetylcholine receptors (nAChRs) in the eye, liver, neuromuscular junction and brain. ${ }^{24,25}$ The structure responsible for these adverse events was hypothesized to be the imidazolyl-pyridine moiety at the end of the side chain, novel to telithromycin. Interestingly, drugs designed to target central nervous system receptors frequently incorporate this moiety. Compounds targeting the central nervous system are potent molecules, generally used in small $(5-10 \mathrm{mg})$ doses. In contrast, doses of antibacterial drugs are typically 50-100-fold greater. In hindsight, large doses of a drug that blocks important nAChR activity offers a plausible explanation for the severe Ketek-related adverse events. Solithromycin's side chain does not contain the imidazolyl-pyridine and is like the older macrolides in that it does not inhibit nACh receptors. $^{24}$ Thus, solithromycin is not expected to have telithromycin-associated side effects. In addition to the unique side chain, solithromycin also has a fluorine at the 2 position of the macrocyclic ring. This fluorine prevents the keto group from enolizing as seen with telithromycin. ${ }^{25}$ The fluorine also interacts with the bacterial ribosome at the peptide tunnel ${ }^{26}$ and confers solithromycin activity against macrolide-resistant strains (including telithromycinresistant strains). Thus, solithromycin has three sites of interaction on the 23S RNA of bacterial ribosomes, making it the 4 th generation of 

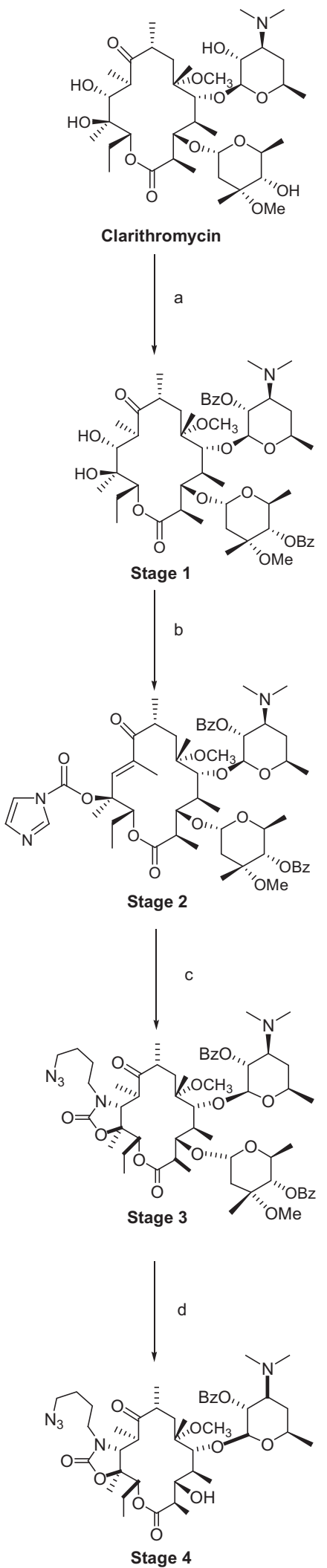

Figure 6 Semi-synthetic route for solithromycin. ${ }^{27,32}$
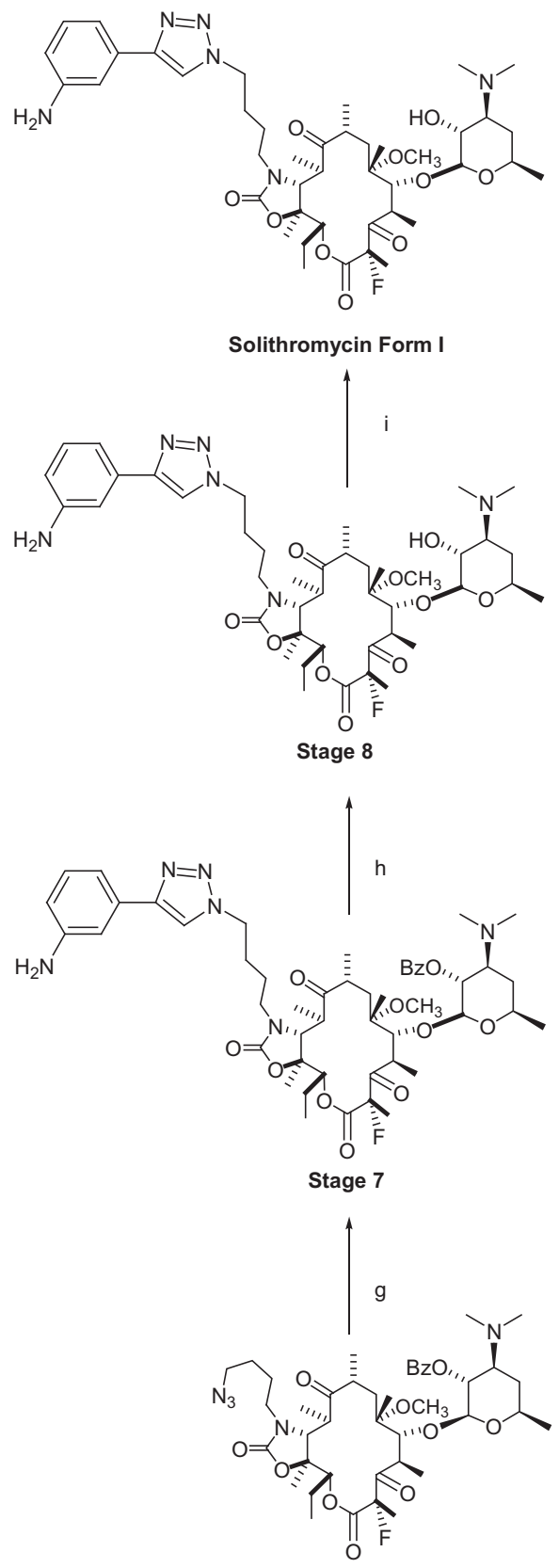

Stage 6

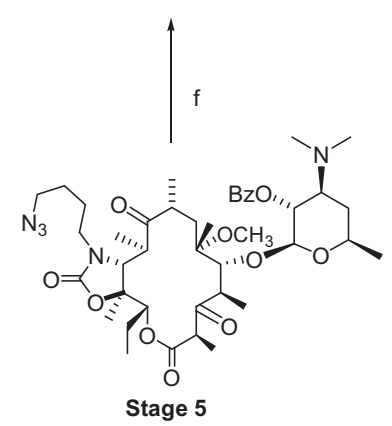


macrolides. Unlike cethromycin, it does not induce CYP3A $4,{ }^{27}$ is well absorbed (oral bioavailability is $63 \%$ and $78 \%$ for $400 \mathrm{mg}$ and $800 \mathrm{mg}$, respectively), ${ }^{28}$ and is well-distributed to tissues and body fluids such as the epithelial lining fluid. ${ }^{27}$ Solithromycin has also been developed as an intravenous formulation. An oral suspension formulation is being tested in pediatric trials. ${ }^{29}$

Following pre-clinical development of solithromycin, two global phase 3 trials for the treatment of moderate to moderately severe community-acquired bacterial pneumonia were successfully completed..$^{30,31}$ At the time that this paper was written, New Drug Applications and a Marketing Authorization Application have been submitted to the regulatory agencies in the US and EU, respectively, for marketing authorizations.

\section{SEMI-SYNTHESIS OF SOLITHROMYCIN}

Solithromycin is a complex molecule having thirteen chiral centers. The manufacture of solithromycin is conducted in the following 9 steps: protection/deprotection of the $2^{\prime}-\mathrm{OH}$ of desosamine, activation of $\mathrm{C}-11$ and $\mathrm{C}-12$, installation of a carbamate at C-11 and C-12, removal of the cladinose, oxidation at $\mathrm{C}-3$, fluorination at $\mathrm{C}-2$, formation of the aryl-1,2,3-triazole moiety and formation of the desired polymorph. ${ }^{27,32}$ The scheme for the semi-synthetic route is shown in Figure 6. The manufacture of solithromycin begins with commercially available clarithromycin. Clarithromycin was chosen as the starting material as it is a convenient way to establish the majority of the chiral centers. However, two new chiral centers are made in the synthesis of solithromycin. In step 3, the 11, 12-carbamate is formed with a high degree of stereochemical control and this transformation is well known in the literature. ${ }^{33-36}$ Creation of a second chiral center occurs during the fluorination at $\mathrm{C}-2$ of the ketolide intermediate. Fluorination with $\mathrm{N}$-Fluorobenzenesulfonimide and a suitable base produces the fluoro-intermediate with the $\mathrm{S}$ configuration. The $\mathrm{R}$ isomer is not observed as a significant side product, indicating that the fluorine adds from one face of the macrolide ring. Attempts to make the $\mathrm{R}$ isomer proved unsuccessful by a number of different approaches, further demonstrating that the fluorination is stereospecific.

The aryl-1,2,3-triazole moiety is another unique feature of solithromycin. Regio-stereoisomer control of the substitution is achieved by employing the copper-catalyzed azide-alkyne cycloaddition methodology. ${ }^{37,38}$ Under copper catalysis, the 1,4-regioisomer is selectively produced from the azide intermediate and 3-ethynylaniline.

Although solithromycin is a challenging molecule to manufacture, the process chemistry from clarithromycin to solithromycin has been demonstrated on the multi-metric ton scale with batch sizes ranging from 250 to $400 \mathrm{~kg}$ depending on the step. At full commercial production, the overall yield from clarithromycin to solithromycin is expected to range from 35 to $40 \%$.

A total synthesis of solithromycin that took 16 steps starting from seven chiral building blocks was recently reported. ${ }^{39}$ These chiral building blocks are in turn built using chiral auxiliaries and chiral catalysts in 23 steps, including those required to make synthetic desosamine. Therefore, 40 chemical transformations (including a step to set the polymorph) are required for the total synthesis of solithromycin via the Meyer chemistry. The ability to manufacture metric tons of solithromycin by this route is yet to be determined.

\section{RECENT ADVANCES}

Wockhardt Ltd. in India has described a new ketolide that also has activity against macrolide-resistant strains (Figure 7). ${ }^{40}$ Their phase 1 results (both single and multiple ascending dose studies) have been

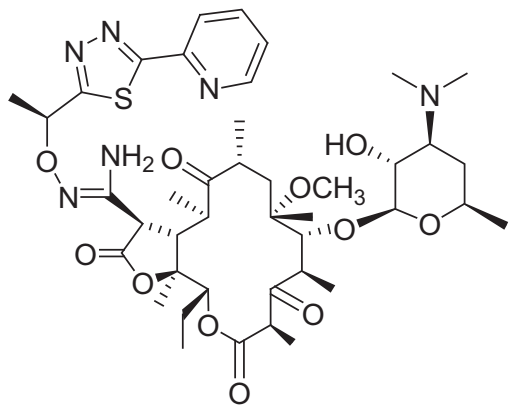

Figure 7 Chemical structure of WCK 4873 (nafithromycin), a lactone ketolide in clinical development by Wockhardt.

announced. ${ }^{41,42}$ This compound, known as WCK 4873 or nafithromycin, has the following unique features: (1) 11, 12- lactone versus the 11, 12-carbamate of telithromycin and solithromycin; (2) the side chain backbone has an amino group and methyl group substituents; (3) the side chain is attached at the 2 position of the pyridine moiety compared with attachment at the 3 position of the pyridine in telithromycin.

Semi-synthetic approaches starting with fermentation derived starting materials have resulted in the synthesis of thousands of analogs by pharmaceutical companies in over a half century since the discovery of erythromycin. ${ }^{6,43,44}$ However, there are some parts of the molecule, such as the substitution at many carbons of the macrocyclic ring, that have not been accessible to chemical modifications. To extend the universe of modifications around the macrocyclic core ring, two main approaches have been taken; biosynthetic and total synthesis. The biosynthetic approach to new molecules is dependent on the expression of genes from $S$. erythreus in a heterologous host, such as Escherichia coli. ${ }^{45}$ Microbes are clever and efficient chemists. New methods to exploit these 'microbial chemists' is the heterologous expression of genes involved in the biosynthesis of macrolides. The genes involved in the macrocyclic or polyketide core are 6-deoxyerythronolide B and deoxysugars as well as the genes involved in self-resistance. To alter macrocycle biosynthesis and obtain 'unnatural' erythromycin compounds, the genes have been heterologously expressed in E. coli. This is a herculean task as there are at least 20 genes involved with the polyketide synthesis. It also requires appropriate substrates. Nonetheless, these hurdles have been overcome with expression of erythromycin and a few macrocyclic analogs. ${ }^{45}$ One very important aspect to a biosynthetic approach to new macrolides is the control of the many chiral centers present in the macrocycle ring. Here, microbial biosynthesis may have an edge over total synthesis.

The total synthesis of macrolide analogs has been reported in the literature for more than 35 years. ${ }^{46-50}$ These approaches have exploited new chemistries to make analogs not available from fermentation derived starting materials. In particular, the Meyer group derived starting materials such as erythromycin developed from chemistry that allows for the synthesis of macrolides and azalides that cannot be prepared from fermentation. A number of chiral building blocks are constructed and then assembled to form macrocycles and azalides with unique ring substitutions brought in with the chiral building blocks. ${ }^{39}$ Such novel macrolides may lead to an enhanced spectrum of activity against Gram-positive organisms and also greater activity against Gram-negative bacteria. However, the processes must be scalable and inexpensive if they are to compete with semi-synthesis or biosynthetic processes.

Azithromycin is used to treat some infections caused by Gram-negative enteric bacteria such as Shigella sp. and Salmonella 
sp. ${ }^{51,52}$ These novel chemistries may enable macrolides to be optimized to address the growing problems of multidrug resistance.

\section{NON-ANTIBACTERIAL USES OF MACROLIDES}

Macrolides have been used for their anti-inflammatory activity ${ }^{4,53}$ and to induce intestinal contractions through binding and activation of the motilin receptor. ${ }^{54}$ These and other uses expand the utility of macrolides to treat other disease states. ${ }^{55}$

\section{CONCLUSIONS}

Macrolides have been an essential class of antibiotics in the physician's armamentarium. Macrolide resistance has decreased their utility in the treatment of respiratory tract infections as well as gonorrhea. Solithromycin is poised to become a fourth-generation macrolide for use in community-acquired bacterial pneumonia, as it could be available in oral capsule and IV formulations. The chemistry used to build on the core erythromycin structure to synthesize thousands of macrolides was developed from lessons learned from other macrolides made in nature.

The teachings of Professor Omura emphasize that there is a great deal of diversity among natural macrolides. We can learn from many of these molecules to help us develop newer, more effective antibacterials that will address the growing challenge of antibiotic resistance.

\section{CONFLICT OF INTEREST}

The authors declare no conflict of interest.

\section{ACKNOWLEDGEMENTS}

We thank the staff at Cempra who have worked hard to help in the development of solithromycin, and investors who have supported the company.

\section{DEDICATION}

We would like to dedicate this review paper to Professor Satoshi Omura. Professor Omura is recognized as a global expert in the field of bioorganic chemistry, where his work has focused on the discovery, development and biosynthesis of useful compounds produced by microorganisms, including the macrolide antibiotics. Professor Omura's work on diverse natural products can be used as a wealth of starting molecules for designing future antibiotics. Professor Omura has received many awards, culminating in the Nobel Prize in Medicine and Physiology for his discovery of avermectin in recognition of his tremendous contributions.

1 Jelic, D. \& Antolovic, R. From erythromycin to azithromycin and new potential ribosomebinding antimicrobials. Antibiotics (Basel) 5, 29 (2016).

2 Omura, S. Macrolide Antibiotics: Chemistry Biology, and Practice, 2nd edn (Academic Press, 2002).

3 Zhanel, G. G., Walkty, A. J. \& Karlowsky, J. A. Fidaxomicin: a novel agent for the treatment of Clostridium difficile infection. Can. J. Infect. Dis. Med. Microbiol 26, 305-312 (2015)

4 Kobayashi, Y. et al. A novel macrolide solithromycin exerts superior anti-inflammatory effect via NF-kB inhibition. J. Pharmacol. Exp. Ther. 345, 76-84 (2013).

5 McGuire, J. et al. Ilotycin, a new antibiotic. Antibiot. Chemother. 2, 281-283 (1952).

6 Katz, L. \& Ashley, G. W. Translation and protein synthesis: macrolides. Chem. Rev. 105, 499-528 (2005).

7 Farrell, D. J., Couturier, C. \& Hryniewicz, W. Distribution and antibacterial susceptibility of macrolide resistance genotypes in Streptococcus pneumoniae: PROTEKT Year 5 (2003-2004). Int. J. Antimicrob. Agents 31, 245-249 (2008).

$8 \mathrm{Kim}, \mathrm{S}$. H. et al. Changing trends in antimicrobial resistance and serotypes of Streptococcus pneumoniae isolates in Asian countries: an Asian Network for Surveillance of Resistant Pathogens (ANSORP) study. Antimicrob. Agents Chemother. 56, 1418-1426 (2012).

9 Bryskier, A. New research in macrolides and ketolides since 1997. Expert Opin. Investig. Drugs 8, 1171-1194 (1999).

10 Fernandes, P. B., Baker, W. R., Freiberg, L. A., Hardy, D. J. \& McDonald, E. J. New macrolides active against Streptococcus pyogenes with inducible or constitutive type of macrolide-lincosamide-streptogramin B resistance. Antimicrob. Agents Chemother. 33, 78-81 (1989).

11 Omura, S. \& Tishler, M. Relationship of structures and microbiological activities of the 16-membered macrolides. J. Med. Chem. 15, 1011-1015 (1972).

12 Xue, Y., Zhao, L., Liu, H. W. \& Sherman, D. H. A gene cluster for macrolide antibiotic biosynthesis in Streptomyces venezuelae: architecture of metabolic diversity. Proc. Natl Acad. Sci. USA 95(21), 12111-12116 (1998).

13 Shi, J., Montay, G. \& Bhargava, V. O. Clinical pharmacokinetics of telithromycin, the first ketolide antibacterial. Clin. Pharmacokinet. 44, 915-934 (2005).

14 Asaka, T., Manaka, A. \& Sugiyama, H. Recent developments in macrolide antimicrobial research. Curr. Top. Med. Chem. 3, 961-989 (2003).

15 Berisio, R. et al. Structural insight into the antibiotic action of telithromycin against resistant mutants. J. Bacteriol. 185, 4276-4279 (2003).

16 Ross, D. B. The FDA and the case of Ketek. N. Engl. J. Med. 356, 1601-1604 (2007).

17 FDA. Briefing Document for Telithromycin (Ketek), Joint Meeting of the Anti-Infective Drug Advisory Committee, Drug Safety and Risk Management Advisory Committee. http://www. fda.gov/ohrms/dockets/ac/06/briefing/2006-4266b1-02-01-FDA-DAIOP.pdf (2006).

18 FDA. Telithromycin (marketed as Ketek) Information http://www.fda.gov/drugs/drugsafety/postmarketdrugsafetyinformationforpatientsandproviders/ucm107824.htm (2007).

19 Hammerschlag, M. R. Use of cethromycin, a new ketolide, for treatment of communityacquired respiratory infections. Expert Opin. Investig. Drugs 17, 387-400 (2008).

20 FDA. Cethromycin Briefing Document for the Anti-Infective Drugs Advisory Committee. http://www.fda.gov/downloads/AdvisoryCommittees/CommitteesMeetingMaterials/Drugs/ Anti-InfectiveDrugsAdvisoryCommittee/UCM161850.pdf (2009).

21 Sato, T. et al. In vitro antibacterial activity of modithromycin, a novel 6,11-bridged bicyclolide, against respiratory pathogens, including macrolide-resistant Grampositive cocci. Antimicrob. Agents Chemother. 55, 1588-1593 (2011).

22 Fernandes, P. Sanchez, S. \& Demain, A.L. Antibiotics: Current Innovations and Future Trends 375-393 (Caister Academic Press, Norfolk, UK, 2015).

23 Pereira, D., Li, J., Fernandes, P. \& Matsa, S. Pikromycin derivative of solithromycin: discussion of activity. 52nd Interscience Conference on Antimicrobial Agents and Chemotherapy No. F1505 (San Francisco, CA, 2012).

24 Bertrand, D., Bertrand, S., Neveu, E. \& Fernandes, P. Molecular characterization of offtarget activities of telithromycin: a potential role for nicotinic acetylcholine receptors. Antimicrob. Agents Chemother. 54, 5399-5402 (2010).

25 Fernandes, P., Martens, E., Bertrand, D. \& Pereira, D. The solithromycin journey-lt is all in the chemistry. Bioorg. Med. Chem pii: S0968-0896, 30642-30643 (2016).

26 Llano-Sotelo, B. et al. Binding and action of CEM-101, a new fluoroketolide antibiotic that inhibits protein synthesis. Antimicrob. Agents Chemother. 54, 4961-4970 (2010).

27 Fernandes, P., Pereira, D., Jamieson, B. \& Keedy, K. Solithromycin. Macrolide antibiotic. Drugs Future 36, 751-758 (2011).

28 Still, J. G. et al. Pharmacokinetics of solithromycin (CEM-101) after single or multiple oral doses and effects of food on single-dose bioavailability in healthy adult subjects. Antimicrob. Agents Chemother. 55, 1997-2003 (2011).

29 Gonzalez, D. et al. Solithromycin pharmacokinetics in plasma and dried blood spots and safety in adolescents. Antimicrob. Agents Chemother. 60, 2572-2576 (2016).

30 Barrera, C. M. et al. Efficacy and safety of oral solithromycin versus oral moxifloxacin for treatment of community-acquired bacterial pneumonia: a global, double-blind, multicentre, randomised, active-controlled, non-inferiority trial (SOLITAIRE-ORAL). Lancet Infect. Dis. 16, 421-430 (2016).

31 File, T. M. Jr. et al. SOLITAIRE-IV: A randomized, double-blind, multicenter study comparing the efficacy and safety of intravenous-to-oral solithromycin to intravenous-tooral moxifloxacin for treatment of community-acquired bacterial pneumonia. Clin. Infect. Dis. 63, 1007-1016 (2016).

32 Pereira, D., Patel, M. \& Deo, K. (Cempra, Inc.). Process for the preparation of macrolide antibacterial agents W02009055557 (2009).

33 Baker, W. R., Clark, J. D., Stephens, R. L. \& Kim, K. H. Modification of macrolide antibiotics. Synthesis of 11-deoxy-11-(carboxyamino)-6-0-methylerythromycin A 11,12-(cyclic esters) via an intramolecular Michael reaction of 0-carbamates with an alpha, beta-unsaturated ketone. J. Org. Chem. 53, 2340-2345 (1988).

$34 \mathrm{Li}$, B. et al. Process development of a novel azetidinyl ketolide antibiotic. Org. Process Res. Dev. 16, 788-797 (2012).

$35 \mathrm{Wu}$, Y. J. \& Su, W. G. Recent developments on ketolides and macrolides. Curr. Med. Chem. 8, 1727-1758 (2001).

36 Hwang, C. et al. SAR of 11,12-carbamate macrolides/ketolides linked with 1,4substituted [1,2,3]-triazoles. 48th Interscience Conference on Antimicrobial Agents and Chemotherapy /Infectious Diseases Society of America 46th Annual Meeting, No. F1-3973 (Washington, DC, USA, 2008).

37 Tornoe, C. W., Christensen, C. \& Meldal, M. Peptidotriazoles on solid phase: [1,2,3]triazoles by regiospecific copper(i)-catalyzed 1,3-dipolar cycloadditions of terminal alkynes to azides. J. Org. Chem. 67, 3057-3064 (2002).

38 Rostovtsev, V. V., Green, L. G., Fokin, V. V. \& Sharpless, K. B. A stepwise huisgen cycloaddition process: copper(I)-catalyzed regioselective "ligation" of azides and terminal alkynes. Angew. Chem. Int. Ed. Engl. 41, 2596-2599 (2002).

39 Seiple, I. B. et al. A platform for the discovery of new macrolide antibiotics. Nature 533 , 338-345 (2016).

40 Satav, J., Takalkar, S., Kulkarni, A., Bhagwat, S. \& Patel, M. WCK 4873 (Nafithromycin): In vitro and in vivo activity of novel lactone-ketolide, against clinically relevant S. pneumoniae (SPN) resistotypes and methicillin-sensitive $S$. aureus (MSSA) (American Society for Microbiology (ASM/Microbe) No. 456, Boston, MA, USA, 2016). 
41 Bhatia, A., Chugh, R., Gupta, M. \& Iwanowski, P. Nafithromycin single ascending dose (SAD) and food effect (FE) study in healthy subjects (American Society for Microbiology (ASM/Microbe) No. 514, Boston, MA, USA, 2016).

42 Chugh, R., Gupta, M., Iwanowski, P. \& Bhatia, A. Nafithromycin phase 1 multiple ascending dose study in healthy subjects. (American Society for Microbiology, (ASM/ Microbe) No. 513, Boston, MA, USA, 2016).

43 Magee, T. V. et al. Discovery of azetidinyl ketolides for the treatment of susceptible and multidrug resistant community-acquired respiratory tract infections. J. Med. Chem. 52, 7446-7457 (2009).

44 Takashima, H. Structural consideration of macrolide antibiotics in relation to the ribosomal interaction and drug design. Curr. Top. Med. Chem. 3, 991-999 (2003).

45 Zhang, H., Wang, Y., Wu, J., Skalina, K. \& Pfeifer, B. A. Complete biosynthesis of erythromycin $A$ and designed analogs using $E$. coli as a heterologous host. Chem. Biol. $17,1232-1240$ (2010).

46 Woodward, R. B. et al. Asymmetric total synthesis of erythromycin. 1. Synthesis of an erythronolide A secoacid derivative via asymmetric induction. J. Am. Chem. Soc. 103 3210-3213 (1981).

47 Woodward, R. B. et al. Asymmetric total synthesis of erythromycin. 2. Synthesis of an erythronolide A lactone system. J. Am. Chem. Soc. 103, 3213-3215 (1981).

48 Woodward, R. B. et al. Asymmetric total synthesis of erythromycin. 3. Total synthesis of erythromycin. J. Am. Chem. Soc. 103, 3215-3217 (1981).

49 Parenty, A., Moreau, X. \& Campagne, J. M. Macrolactonizations in the total synthesis of natural products. Chem. Rev. 106, 911-939 (2006).

50 Breton, P. et al. Total synthesis of erythromycin B. Tetrahedron 63, 5709-5729 (2007).

51 Poramathikul, K. et al. Multidrug-resistant Shigella infections in patients with diarrhea, Cambodia, 2014-2015. Emerg. Infect. Dis. 22, 1640-1643 (2016).
52 Crump, J. A. \& Heyderman, R. S. A perspective on invasive Salmonella disease in Africa. Clin. Infect. Dis. 61(Suppl 4), S235-S240 (2015).

53 Kobayashi, Y. et al. A novel macrolide/fluoroketolide, solithromycin (CEM-101), reverses corticosteroid insensitivity via phosphoinositide 3-kinase pathway inhibition. Br. J. Pharmacol. 169, 1024-1034 (2013).

54 Mitselos, A. Vanden Berghe, P., Peeters, T. L. \& Depoortere, I. Differences in motilin receptor desensitization after stimulation with motilin or motilides are due to alternative receptor trafficking. Biochem. Pharmacol. 75, 1115-1128 (2008).

55 Kudoh, S., Azuma, A., Yamamoto, M., Izumi, T. \& Ando, M. Improvement of survival in patients with diffuse panbronchiolitis treated with low-dose erythromycin. Am. J. Respir Crit. Care Med. 157(6 Pt 1), 1829-1832 (1998).

cc) (1) $(9)$ This work is licensed under a Creative Commons Attribution-NonCommercial-NoDerivs 4.0 Interna-

tional License. The images or other third party material in this article are included in the article's Creative Commons license, unless indicated otherwise in the credit line; if the material is not included under the Creative Commons license, users will need to obtain permission from the license holder to reproduce the material. To view a copy of this license, visit http://creativecommons.org/licenses/bync-nd/4.0/

(C) The Author(s) 2017 